\title{
Cerebral cortical potentials to pure non-painful temperature stimulation: an objective technique for the assessment of small fibre pathway in man
}

\author{
GORAN A JAMAL, * STIG HANSEN, $†$ ANDREW I WEIR, JOHN P BALLANTYNE* \\ From Glasgow University Department of Neurology, Institute of Neurological Sciences, ${ }^{*}$ and West of Scotland \\ Health Board's Department of Clinical Physics and Bioengineering, $†$ Glasgow, UK
}

SUMMARY In six healthy subjects cortical potentials were evoked by rapidly changing heating or cooling stimuli to the hand. Recordings were made from the contralateral scalp area overlying the sensori-motor cortex, referred to a frontal reference. The potential averaged from 25 stimuli comprised a large positive wave with a mean amplitude of $9 \cdot 2, \mathrm{SD} 1 \cdot 1 \mu \mathrm{V}$ for heat and $8.8 \mathrm{SD} 1 \cdot 2 \mu \mathrm{V}$ for cold stimulation. The heat evoked potentials had longer peak latencies (range: $280-350 \mathrm{~ms}$ ) than those elicited by cold stimuli (range: $178-200 \mathrm{~ms}$ ). A lower amplitude positive wave of a longer latency was also recorded to both modes of stimulation over the corresponding ipsilateral cortex. Cortical thermal evoked potentials were absent in two patients, one with severe selective small fibre neuropathy and the other with syringomyelia, both of whom had high thermal thresholds demonstrated by the technique of Jamal et al. ${ }^{\prime}$ Cerebral potentials evoked by thermal stimuli may represent an alternative approach to the investigation of the central projections of the human small fibre system with both clinical and research potential.

Conventional peripheral sensory nerve conduction and somatosensory evoked potential (SEP) studies allow the assessment of function in the peripheral and central projections of large fibre afferent pathways. ${ }^{23}$ These methods provide no information on the integrity of the unmyelinated $(C)$ and the thinly myelinated $(A \delta)$ peripheral nerve fibres or their central pathways. ${ }^{23}$ Cortical potentials, evoked by large fibre activation are recorded by transcutaneous electrical stimulation of peripheral nerves ${ }^{4}$ or by modality specific stimulation of their end organs. ${ }^{5-8}$

Peripheral nerve fibres serving cold sensation are in the range of thinly myelinated $(\mathbf{A} \delta)$ group while fibres serving warm receptors are unmyelinated. -11 $^{-11}$ Measurement of the perception thresholds to graded heat or cold stimuli represents one method of evaluation of the functional integrity of these fibre populations and their central pathways. ${ }^{12-15}$ The recording of cortical responses to heat and cold stimuli may offer an alternative objective method of assessment. There have been attempts in the past with varying success to record cortical potentials to thermal stimulation of the

Address for reprint requests: Dr Goran A Jamal, Glasgow University Department of Neurology, Institute of Neurological Sciences, Southern General Hospital, Glasgow G51 4TF, UK.

Received 5 February 1988 and in revised form 21 July 1988. Accepted 6 September 1988 extremities. Duclaux et al ${ }^{16}$ recorded cortical potentials to cooling of the hand in 10 out of 12 young healthy subjects. Chatt and Kenshalo ${ }^{17}$ recorded evoked potentials to cooling of the hand in two healthy subjects. Most attempts to record cortical potentials to heat stimulation of the extremities have failed ${ }^{161819}$ but Fruhstorfer and colleagues ${ }^{20}$ recorded such cortical potentials to hand stimulation from eight of 15 healthy individuals. Chatt and Kenshalo ${ }^{21}$ were also successful in recording cortical potentials to heat stimulation of the hand in three normal subjects.

The purpose of our research in this field is to obtain more consistent results by modification of both the stimulation and recording techniques. We have used a system, designed in our laboratory and capable of delivering heat and cold stimuli of defined onset, high rates of temperature change and free of tactile cues. This is a preliminary report of the results of the application of our method in six control subjects and two patients with selective involvement of small fibre pathways.

\section{Methods}

Cutaneous thermal stimulation for the recording of the cerebral evoked potentials was achieved by the use of a stimulator which delivered thermal stimuli free of tactile cues. The stimulating system used is a modification of that 


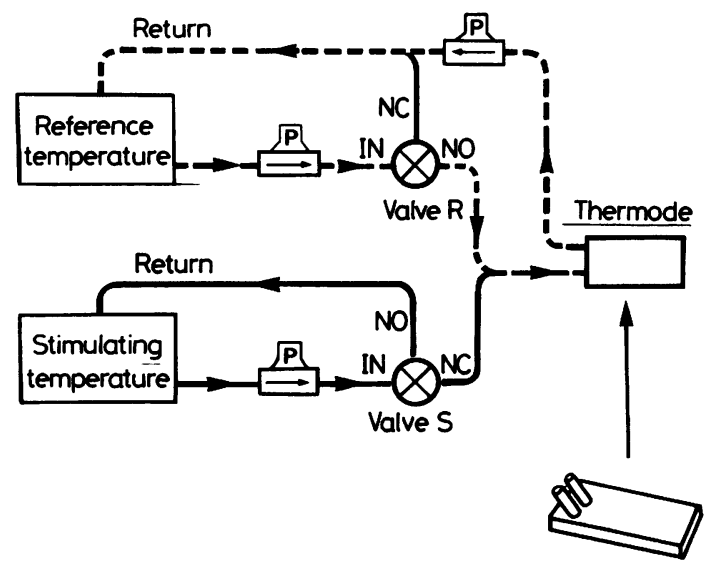

Fig 1 Diagram of the thermal evoked potential system. $S$ and $R$ : solenoid valves. NO: normally open (closes when the solenoids are activated). NC: normally closed (opens when the solenoids are activated). IN: valve inlet. P: water pump.

described by Hensel et al. ${ }^{22}$ Figure 1 is a diagrammatic representation of the method. The stimulator, with a $12.5 \mathrm{~cm}^{2}$ surface area, is a thin walled copper box, of low heat capacity to facilitate the delivery of a rapid changing thermal stimulus. The temperature of the thermode is measured by a thermocouple bonded to the surface in contact with the skin. The thermode is connected to two thermostatically controlled waterbaths. The desired basic skin temperature (reference temperature) is maintained by water from bath 1 circulating through the thermode. Thermal stimuli are superimposed thereon by the activation of solenoid valves $R$ and $S$ which switch the water circulation to bath 2 (solid lines, fig 1). The amplitude and rate of change of the thermal stimulation are set by adjustment of the temperature of the stimulating waterbath and the duration of opening of the solenoid valves. Heat stimuli to $8^{\circ} \mathrm{C}$ above and cold stimuli to $6^{\circ} \mathrm{C}$ below basic skin temperature were used. In both cases the rate of temperature change was $21^{\circ} \mathrm{C} / \mathrm{s}$.

Repeated recordings of the thermode temperature during stimulation showed that the thermal ramp of stimulus starts $370 \mathrm{~ms}$ after electrical activation of the solenoid valves, which is the time required for water from the second circuit (solid lines fig 1) to fill the tubing common to both circuits. We estimate a measuring accuracy in the stimulation start values at less than $2 \mathrm{~ms}$. The signal averager is triggered simultaneously with the activation of the solenoid valves.

Thermal stimulation (heat or cold) is applied to the dorsal aspect of the hand. The reference temperature of the skin upon which the stimuli are superimposed is $35^{\circ} \mathrm{C}$ and $30^{\circ} \mathrm{C}$ for heat and cold stimulation respectively. The signals from the scalp electrodes are averaged on-line using a Medelec Sensor evoked potential system with a band pass of 0.3 to $30 \mathrm{~Hz}$. Analysis time is set at one second and the potentials from 25 stimulations are averaged. Cortical potentials are recorded from the scalp using padded silver electrodes placed at one or more of the positions $\mathrm{C}_{3}, \mathrm{C}_{4}, \mathrm{C}_{2}, \mathrm{~F}_{\mathrm{pl}}, \mathrm{O}_{1}$ and referred to $F_{z}$ according to the 10-20 international EEG system. ${ }^{23}$ The contribution to the potentials from this reference were investigated by comparison with potentials recorded using an ipsilateral shoulder reference. Repeat trials were performed to assess the reproducibility of the recorded potentials.

\section{Control subjects and patients}

Six healthy subjects aged 24 to 38 years were studied. The method was also applied to two patients with clinically diagnosed small fibre pathway dysfunction. Details of the patients and control subjects are given in the results section.

\section{Results}

\section{Control subjects}

Both heat and cold stimulation of the dorsal aspect of the right hand evoked well defined cortical potentials recorded between $\mathrm{C}_{3}$ and $\mathrm{F}_{2}$ in the six healthy subjects (figs 2 and 3). To heat stimulation, a large positive peak with latency 278 to 350 (mean 302.3; SD 25.6) ms and amplitude 7.6 to 11 (mean 9.2; SD 1.1) $\mu \mathrm{V}$ was recorded. It was followed in some subjects by a large negative wave. The wave complex seen in all recordings at $100-200 \mathrm{~ms}$ after the electrical activation of the solenoid valve $(E)$ is thought to be a slow vertex potential evoked by the sound caused by the activation of the solenoid valves. It does not interfere with the thermally evoked potentials. A control recording was made in a subject listening to white noise through headphones. The slow vertex potential was absent while the thermal potential remained. A recording made without a thermode in place demonstrated this wave complex without the thermal potential.

Figure 4 shows the potentials in one control subject recorded simultaneously from electrodes at positions $\mathrm{C}_{3}, \mathrm{C}_{2}, \mathrm{~F}_{\mathrm{pl}}$ and $\mathrm{O}_{1}$ (reference $\mathrm{F}_{\mathrm{z}}$ ) to heat stimulation of the right hand. A positive potential of similar latency but smaller amplitude to that at $\mathrm{C}_{3}$ was recorded from the $\mathrm{C}_{\mathrm{z}}$ electrode. No potential was identified from positions $\mathrm{F}_{\mathrm{p} 1}$ and $\mathrm{O}_{1}$. In three subjects an electrode placed over the ipsilateral sensory cortex $\left(\mathrm{C}_{4}\right.$ position $)$ recorded reproducible potentials of much smaller amplitudes (mean $4.3 \mu \mathrm{V}$ ) and latencies on average $45 \mathrm{~ms}$ greater than those recorded from the contralateral sensory cortex $\left(C_{3}\right.$ position) (fig 5$)$. There was very little difference in the potentials recorded whether $F_{2}$ or the ipsilateral shoulder was used as a reference indicating that the $F_{z}$ reference is relatively inactive. Similar positive cortical potentials were recorded from cold stimulation of the dorsum of the right hand in these subjects (fig 3). These potentials had similar amplitudes (mean $=8.8 ; \mathrm{SD}=1.2 \mu \mathrm{V}$ ) but shorter peak latencies (range 178-200; mean = 184 ; SD $=22.3 \mathrm{~ms}$ ) than those evoked to heat stimulation.

\section{Patients}

Patient 1. A 38 year old male patient with type I diabetes mellitus presented with a 3 year history 
Female, 32 years

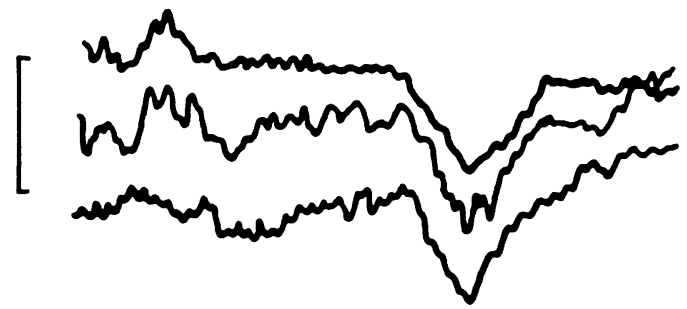

Male, 28 years

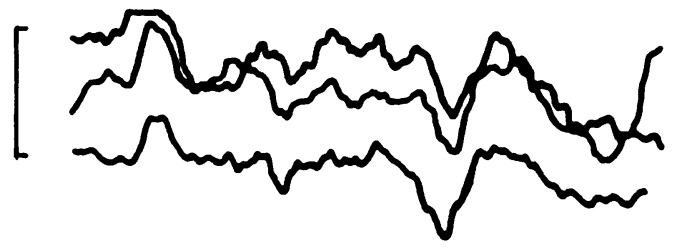

Male, 38 years

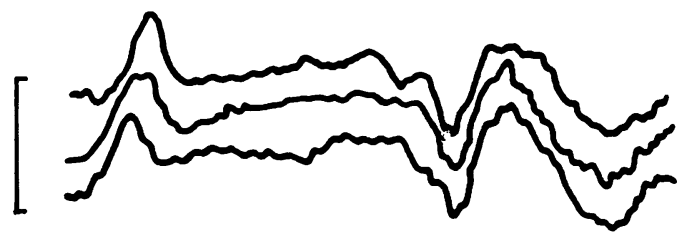

Male, 26 years

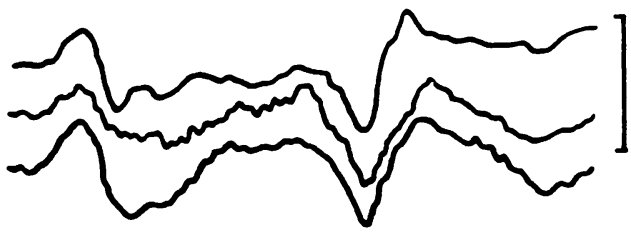

Male, 35 years

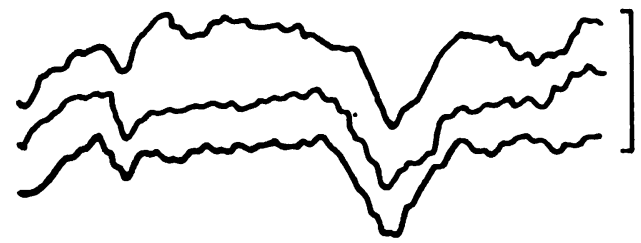

Male, 24 years

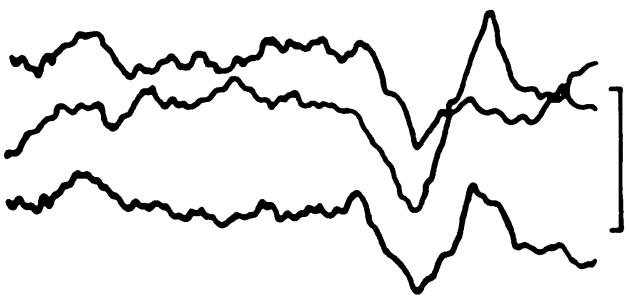

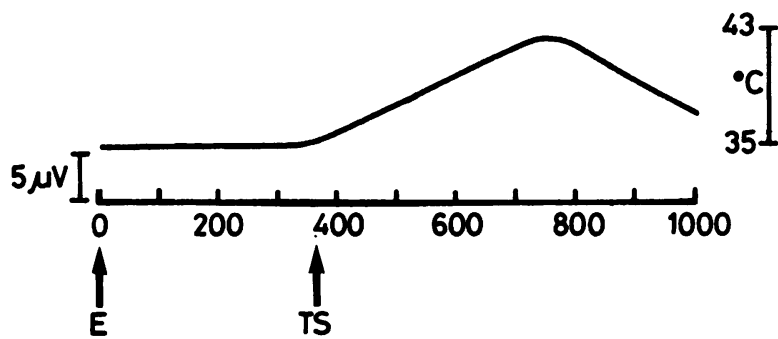

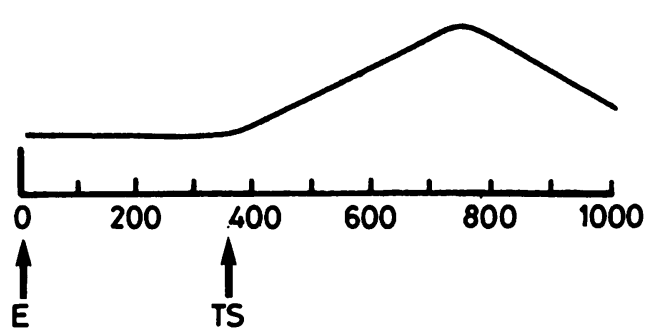

Fig 2 Heat evoked cortical potentials $\left(C_{3}-F_{z}\right)$ to stimulation of the right hand in six subjects repeated on three occasions for each subject. Each trace is an average of at least 25 sweeps. E: onset of the electrical pulse and activation of the solenoid valves. TS: onset of the thermal stimulus.

suggestive of severe selective small fibre neuropathy. His symptoms included constant burning pain in the skin of the soles of the feet, worse at night, a dull deeply seated aching pain in the feet and features of autonomic dysfunction. ${ }^{15}$
Examination revealed reduced pinprick and temperature sensation in both feet below the ankles and both hands below the wrists.

Motor and sensory conductions, EMG and SEP to median and posterior tibial nerve stimulation were 


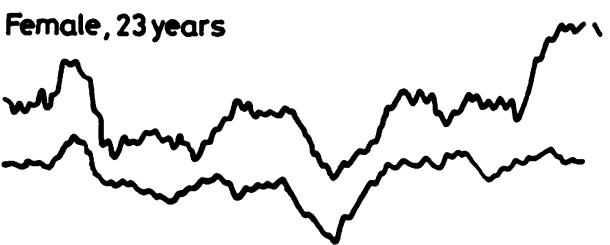

Male. 32 years
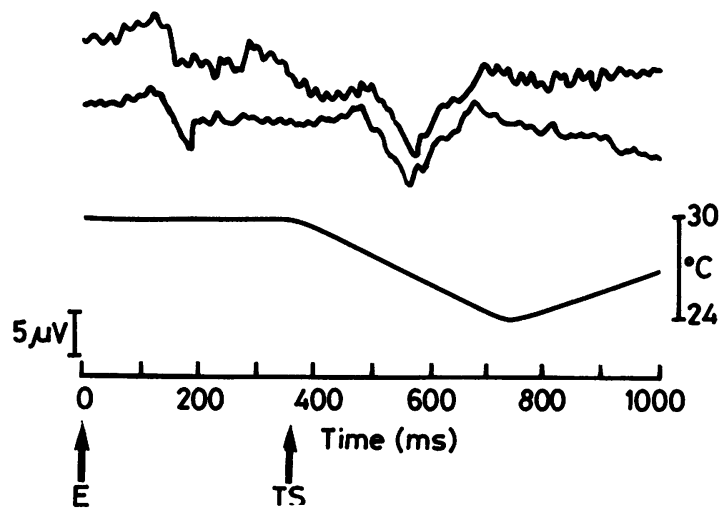

Fig 3 Cold evoked cortical potentials recorded $\left(C_{3}-F_{2}\right)$ to stimulation of the right hand in six subjects repeated on three occasions for each subject. Each trace is an average of at least 25 sweeps. $E$ and TS: as in fig 2.
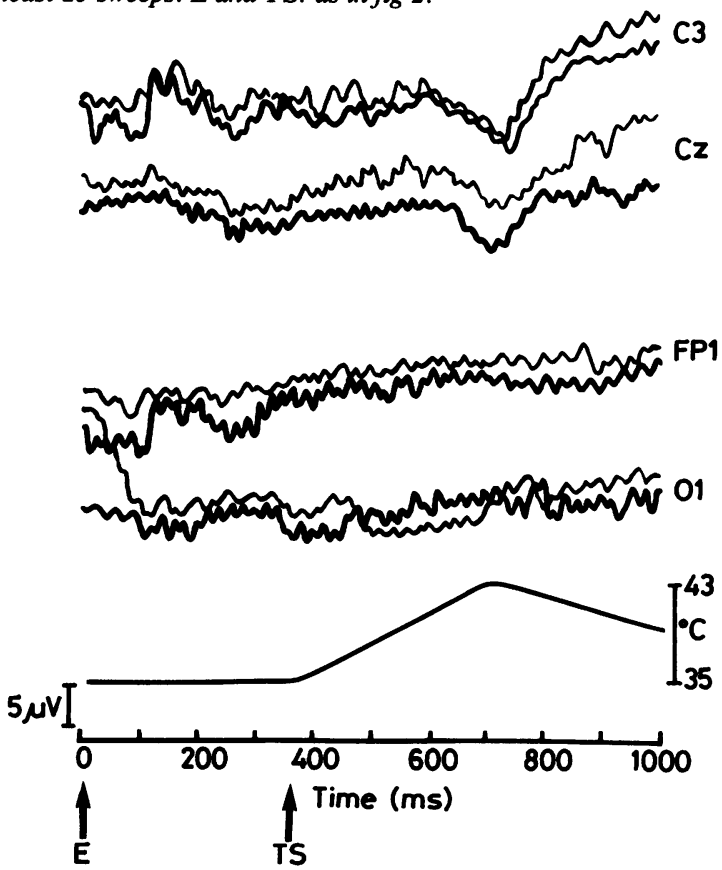

Fig 4 Averaged cortical potentials to heat stimulation of the right hand from a 32 year old female subject. Recording electrodes were in positions $C_{3}, C_{z}, F_{p l}$ and $O$, with reference $F_{z}$. A reproducible potential of smaller amplitude but similar latency was recorded simultaneously from the vertex at $C_{z}$ (in addition to the response from the contralateral sensory cortex). No potentials were obtained at $F_{p 1}$ or $O$, positions. $E$ and TS: as in fig 2.
Female, 23 years

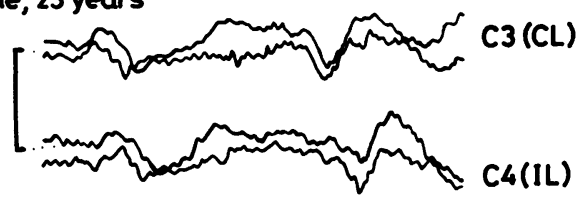

Male, 26 years

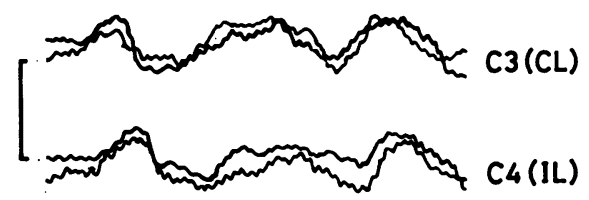

Male, 28 years
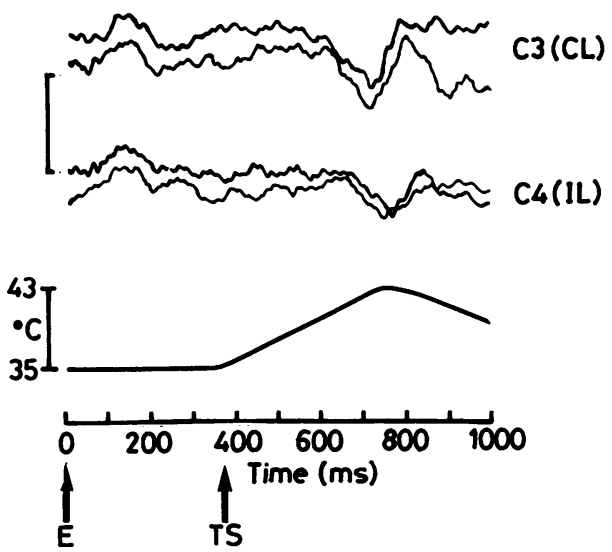

Fig 5 Contralateral (CL) and ipsilateral (IL) heat evoked cortical potentials in three subjects to stimulation of the right hand. In each case, the potential from the scalp overlying the ipsilateral sensory cortex is smaller in amplitude and of longer latency than that recorded from the contralateral sensory cortex. E and TS: as in fig 2.

normal. Quantitative estimation of vibration perception threshold (VPT) using the technique of Goldberg and Lindblom ${ }^{24}$ produced normal values. Heat and cold thermal thresholds, using the method of Jamal et $a l,{ }^{1}$ were abnormally increased in wrist and ankle (see table). Cortical evoked potentials could not be recorded to heat or cold stimulation of either hand (fig 6). Patient 2. This was a 45 year old female with a 15 year history of syringomyelia. There was reduced pinprick and temperature sensation in the entire right upper limb and right upper thorax to below the nipple $\left(\mathrm{C}_{4}-\mathrm{T}_{5}\right.$ dermatones). Vibration, proprioception and twopoint discrimination were normal on clinical testing. The small hand muscles were wasted on the right side with no evidence of a focal lesion of the median or ulnar nerves to account for the appearances. Deep tendon reflexes were absent in the right arm, normal in the left arm and brisk (clonus) in both legs with bilateral extensor plantar reflexes. VPT values were normal in all four limbs. 

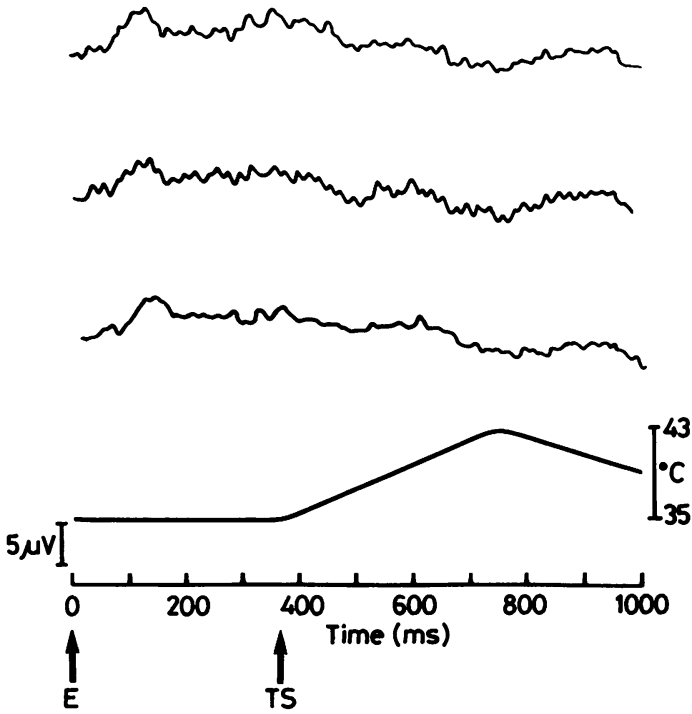

Fig 6 Evoked cortical potentials $\left(C_{3}-F_{z}\right)$ to heat stimulation of the right hand in a 38 year old male patient with small fibre neuropathy and high wrist thermal thresholds. No potentials were obtained from the contralateral sensory cortex to either heat or cold stimulation. Somatosensory evoked potentials were normal. $E$ and TS: as in fig 2.

Heat and cold thermal thresholds were abnormally high at right wrist but normal at left wrist and both ankles (see table). No abnormality of SEP to posterior tibial nerve or median nerve stimulation was found on either side.

Cortical potentials, evoked by thermal stimuli were recorded from stimulation of the left hand. A positive potential of $9.5 \mu \mathrm{V}$ amplitude and 322 ms latency to heat stimulation and of $10.6 \mu \mathrm{V}$ amplitude and $188 \mathrm{~ms}$ latency to cold stimulation were recorded. These values are within the normal range. Stimulation of the right hand failed to evoke cortical potentials (fig 7).

\section{Discussion}

The recording of cortical potentials to thermal stimulation represents an alternative approach to the
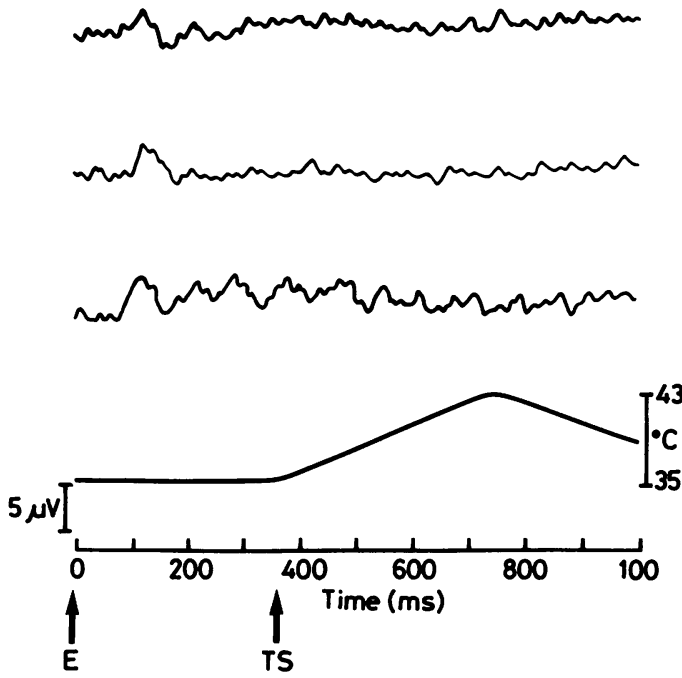

Fig 7 Evoked cortical potentials $\left(C_{3}-F_{2}\right)$ to heat stimulation of the right hand in a 45 year old female patient with syringomyelia. No potentials were obtained from the contralateral sensory cortex to either heat or cold stimulation. The patient had abnormally high thermal thresholds in the same hand. Somatosensory evoked potentials were normal. $E$ and TS: as in fig 2.

investigation of the thermal sensation pathway in man. The identification of a potential apparently restricted to the scalp site overlying the postcentral gyrus suggests that a population of neurons in human cortex are activated by peripheral thermal stimulation. Electrophysiological studies of single units in animals have confirmed the presence of neurons in the primary sensory cortex responding to non-painful thermal stimulation of the extremities. ${ }^{2526}$

There are certain aspects of the methodology that require elaboration. The temperature to which the skin of the hand is adapted is an important factor in the determination of the dynamic response of specific human warm and cold receptors to sudden changes in skin temperature. ${ }^{92-29}$ Basic skin temperatures of $35^{\circ} \mathrm{C}$, for heat stimulation, and of $30^{\circ} \mathrm{C}$ for cold stimulation were chosen as the corresponding

Table Thermal thresholds values for patients and control subjects

\begin{tabular}{|c|c|c|c|c|c|c|}
\hline \multirow[b]{2}{*}{ Site } & & \multicolumn{2}{|c|}{ Normal values } & \multirow{2}{*}{$\frac{\text { Patient I }}{\text { Right }}$} & \multicolumn{2}{|c|}{ Patient 2} \\
\hline & & Mean & $U L N$ & & Left & Right \\
\hline $\begin{array}{l}\text { Wrist } \\
\text { Wrist } \\
\text { Ankle } \\
\text { Ankle }\end{array}$ & $\begin{array}{ll}\mathbf{H T} & {\left[{ }^{\circ} \mathbf{C}\right]} \\
\mathbf{C T} & {\left[{ }^{\circ} \mathbf{C}\right]} \\
\text { HT } & {\left[{ }^{\circ} \mathbf{C}\right]} \\
\mathbf{C T} & {\left[{ }^{\circ} \mathbf{C}\right]}\end{array}$ & $\begin{array}{l}0.23 \\
0.15 \\
1.35 \\
0.17\end{array}$ & $\begin{array}{l}0.40 \\
0.27 \\
3.28 \\
0.32\end{array}$ & $\begin{array}{l}6.65 \\
4.35 \\
8.95 \\
5.45\end{array}$ & $\begin{array}{l}0.25 \\
0.15 \\
1.65 \\
0.25\end{array}$ & $\begin{array}{l}28 \\
28 \\
0.25 \\
0.25\end{array}$ \\
\hline
\end{tabular}

Normal values from Jamal et al.' Values greater than upper limit of normal (ULN) at the $99 \%$ confidence level are in italic. 
receptors show high sensitivity at these skin temperatures. ${ }^{27-29}$ The steeper the rate of change of stimulating temperature, the larger the number of specific thermal units activated, the higher the frequency of discharge produced ${ }^{9728}{ }^{30}$ and the greater the degree of synchrony of the cortical input. Stimulators based on electrical activation of thermoelectric elements were not used as they are incapable of delivering thermal stimuli at a sufficiently high rate of temperature change required in this study. The intensities of thermal stimuli applied are within the range in which specific warm or cold receptors, but not nociceptors, are activated. ${ }^{911}$

The greater latency of heat evoked potentials compared with those elicited by cold stimulation accords well with other observations: specific receptors serve heat and cold sensation, ${ }^{32}$ the reaction time to heat stimulation is longer than that to cold stimulation; ${ }^{31}$ conduction along nerve fibres subserving heat receptors (unmyelinated $\mathrm{C}$ type) is slower than along those serving cold receptors (thinly myelinated A $\delta$ type) (11 $^{1133}$ and heat and cold sensations could be dissociated during differential blocking of peripheral nerves. ${ }^{34} 35$

It is unlikely that the ipsilateral cortical potential arising from thermal stimulation of the hand is due to volume conduction from the contralateral cortex as there is a substantial latency difference between the two potentials (fig 5). Contamination by potentials present at the reference electrode is unlikely since very little difference was noted when the same ipsilateral potential was recorded using an ipsilateral shoulder reference. The ipsilateral potential is, therefore, likely to be a "true" cortical response. Ipsilateral potentials, to electrical stimulation of the median nerve in SEP studies, with longer latencies compared to the contralateral potentials have been recorded in man. ${ }^{636}$ These authors suggested that the latency difference might be a manifestation of interhemispheric conduction time through the corpus callosum. We can only speculate that the ipsilateral potentials to thermal stimuli recorded in our subjects (fig 5) may have a similar explanation. Alternatively the ipsilateral potential could be due to projection of uncrossed ascending thermal fibres to the ipsilateral sensory cortex. Projection of some of the second sensory neurons in the small fibre afferent system to the ipsilateral thalamus through the ipsilateral spino-cervical tract, which predominantly includes afferent cutaneous fibres from the forelimb, has been claimed..$^{37} 38$ The anatomical and functional existence of the spino-cervical tract in man, however, remains to be demonstrated. ${ }^{9}$ Single neurons in both the ipsilateral and contralateral primary sensory cortex of rats have been reported to respond to temperature stimulation of one side of the scrotal skin. ${ }^{39}$ There is also evidence, from psychophysical studies, that simultaneous temperature stimuli applied to bilateral identical sites do summate in $\operatorname{man}^{40} 41$ and it is possible that this phenomenon is a consequence of some sort of interhemispheric connection.

Cortical potentials to thermal stimulation could not be evoked in either patient 1 or the right hand in patient 2 (figs 6 and 7). Abnormality of thermal sensation threshold is found in patients with selective small fibre neuropathy and this is probably due to the involvement of the specific thermal receptors and/or nerve fibres serving thermal sensation. ${ }^{42}$ The absence of thermal evoked cortical potentials in patient 1 is, therefore, likely to be due to failure to produce an adequate afferent volley in the peripheral nerve.

The abnormality of thermal sensation in patient 2 with absent cortical responses to the stimulation of the right hand (fig 7), unilateral clinical evidence of small fibre dysfunction and the elevation of thermal thresholds in the right upper limb is probably due to the involvement of thermal pathway in the spinal cord by the syrinx. The likely site of involvement is the anterior commissure.

These investigations were designed to test the hypothesis that recording of thermal evoked potentials may be of value in small fibre ablation syndromes. We would concede that in the patients studied the absence of such potentials may not have added to the definition of the pathophysiological deficit. It serves to demonstrate, however, that the results of thermal ${ }^{\infty}-$ evoked potential application correlates with the evidence of marked dysfunction in small fibre peripheral or central pathways shown by clinical examination and thermal threshold testing and thus produced the "expected" result in these circumstances. The results encourage further exploration of the application of the technique in marginally abnormal cases in which circumstance the technique would then be of obvious clinical benefit. The technique may yield information on whether the thalamic neurons in man project their thermal input to the cerebral cortex.

We are grateful to Professor J A Simpson for advice and to Mrs Kathleen Phillipson for secretarial assistance. Financial support was received from the Glasgow University Department of Neurology Research Fund.

\section{References}

I Jamal GA, Hansen S, Weir AI, Ballantyne JP. An improved automated method for the measurement of thermal thresholds. 1. Normal subjects. J Neurol Neurosurg Psychiatry 1985;48:354-60.

2 Buchthal F, Rosenfalck AW, Behse FR. Sensory potentials of normal and diseased nerves. In: Dyck PJ, Thomas PK, Lambert EH, Bunge R, eds. Peripheral Neuropathy. London: WB Saunders, 1984;Vol 1:981-1015.

3 Desmedt JE. Somatosensory cerebral evoked potentials in man. 
In: Cobb WA, ed. Handbook of Electroencephalography and Clinical Neurophysiology. Amsterdam: Elsevier, 1971;Vol 9: 55-82.

4 Dawson GD. A summation technique for the detection of small evoked potentials. Electroencephalogr Clin Neurophysiol 1954;6:65-84.

5 Nakanishi T, Shimada Y, Toyokura Y. Somatosensory evoked responses to mechanical stimulation in normal subjects and in patients with neurological disorders. J Neurol Sci 1974;21: 289-98.

6 Salamy A. Commissural transmission: maturational changes in humans. Science 1978;200:1409-11.

7 Franzen O, Offenloch $\mathbf{K}$. Evoked response correlates of psychological magnitude estimates of tactile stimulation in man. Exp Brain Res 1969;8:1-8.

8 Stowell H. Latency characteristics of primary somatosensory potentials evoked by electrical and mechanical stimuli. Int J Psychobiol 1972;2:305-20.

9 Hensel H. Thermal Sensation and Thermoreceptors in Man. Illinois, Springfield: Thomas 1982.

10 Hensel $\mathrm{H}$, Boman $\mathrm{K}$. Afferent impulses in cutaneous sensory nerves in human subjects. $J$ Neurophysiol 1960;23:564-78.

11 Iggo A. Cutaneous thermoreceptors in primates and subprimates. J Physiol (Lond) 1969;200:403-30.

12 Fruhstorfer HG, Lindblom U, Schmidt WG. Method for quantitative estimation of thermal thresholds in patients. $J$ Neurol Neurosurg Psychiatry 1976;39:1071-5.

13 Dyck PJ, Zimmerman IR, O'Brien PC. Introduction of automated systems to evaluate touch-pressure, vibration and thermal cutaneous sensation in man. Ann Neurol 1978;4:502-10.

14 Jamal GA, Weir AI, Hansen S, Ballantyne JP. An improved automated method for the measurement of thermal thresholds. 2. Patients with peripheral neuropathy. $J$ Neurol Neurosurg Psychiatry 1985;48:361-6.

15 Jamal GA, Hansen S, Weir AI, Ballantyne JP. The neurophysiologic investigation of small fiber neuropathies. Muscle Nerve 1987;10:537-45.

6 Duclaux R, Franzen O, Chatt AB, Kenshalo DR, Stowell H. Responses recorded from human scalp evoked by cutaneous thermal stimulation. Brain Res 1974;78:279-90.

17 Chatt AB, Kenshalo DR. The afferent fiber population mediating the thermal evoked response to skin cooling in man. Exp Neurol 1979;64:146-54.

18 Fruhstorfer H, Guth H, Pfaff U. Cortical responses evoked by thermal stimuli in man. Pflugers Archiv 1973;339:R88.

19 Carmon A, Mor A, Goldberg J. Evoked cerebral responses to noxious thermal stimuli in humans. Exp Brain Res 1976;25: 103-7.

20 Fruhstorfer H, Guth H, Pfaff U. Cortical responses evoked by thermal stimuli in man. In: McCallum WC, Knott R, eds. The Responsive Brain. Bristol: Wright \& Sons, 1976:30-3.

21 Chatt AB, Kenshalo DR. Cerebral evoked responses to skin warming recorded from human scalp. Exp Brain Res 1977;28:449-55.

22 Hensel H, Strom L, Zotterman Y. Electrophysiological measurements of depth of thermoreceptors. J Neurophysiol 1951:14:423-9.
23 Jasper HH. The 10-20 electrode system of the International Federation. Electroencephalogr Clin Neurophysiol 1958;10: 371-5.

24 Goldberg JM, Lindblom U. Standardised method of determining vibratory perception thresholds for diagnosis and screening in neurological investigation. $J$ Neurol Neurosurg Psychiatry 1979;42:793-802.

25 Chatt AB, Kenshalo DR. Cells located in somatosensory cortex of the cat specifically sensitive to skin temperature. Soc Neurosci Abstr 1977;3:479.

26 Kreisman NR, Zimmerman ID. Cortical unit responses to temperature stimulation of the skin. Brain Res 1971;25:184-7.

27 Konietzny F, Hensel $H$. The dynamic response of warm units in human skin nerves. Plugers Archiv 1977;370:111-4.

28 Konietzny F, Hensel H. The neural basis of the sensory quality of warmth. In: Kenshalo DR, ed. Sensory Functions of the Skins of Humans. London: Plenum Press, 1980;241-56.

29 Jarvilehto $T$, Hamalainen $H$. Touch and thermal sensations: Psychophysical observations and unit activity in human skin nerves. In: Kenshalo DR, ed. Sensory Functions of the Skins of Humans. London: Plenum Press, 1980:279-95.

30 Darian-Smith I, Johnson KO, LaMotte C, Kenins P, Shigenaga Y, Ming CV. Coding of incremental changes in skin temperature by single warm fibres in the monkey. $J$ Neurophysiol 1979; 42:1316-31.

31 Fruhstorfer $\mathbf{H}$, Guth $\mathbf{H}$, Pfaff $U$. Thermal reaction time as a function of stimulation site. Plugers Archiv 1972;335:R49.

32 Iggo A. Morphology of cutaneous receptors. Ann Rev Neurosci 1982;5:1-31.

33 Torebjork HE, Hallin RG. Skin receptors supplied by unmyelinated (C) fibres in man. In: Zotterman Y, ed. Sensory Functions of Skin in Primates. Oxford: Pergamon Press, 1976:475-85.

34 Fruhstorfer H, Zenz M, Nolte H, Hensel H. Dissociated loss of cold and warm sensibility during regional anaesthesia. Pflugers Archiv 1974;349:73-82.

35 Mackenzie RA, Burke D, Skuse NF, Lethlean AK. Fibre function and perception during cutaneous nerve block. J Neurol Neurosurg Psychiatry 1975;38:865-73.

36 Tamura K. Ipsilateral somatosensory evoked responses in man. Folia Psychiatr Neurol Jpn 1972;26:83-94.

37 Brown AG. Ascending and long spinal pathways: dorsal columns, spinocervical tract and spinothalamic tract. In: Iggo A, ed. Handbook of Sensory Physiology Berlin: Springer, 1973;Vol 2:315-38.

38 Cervero F, Iggo A, Molony V. Responses of spinocervical tract neurones to noxious stimulation of the skin. J Physiol (Lond) 1977;267:537-58.

39 Hellon RF, Mitchell D. Convergence in a thermal afferent pathway in the rat. J Physiol (Lond) 1975;248:359-76.

40 Marks LE, Stevens JC. Spatial summation of warmth: influence of duration and configuration of the stimulus. Am $J$ Psychol 1973;86:251-67.

41 Kenshalo DR. Biophysics and psychophysics of feeling. In: Carterette EC, Friedman MP, eds. Handbook of perception. New York: Academic Press, 1978;Vol 6B:29-74.

42 Jamal GA. A Quantitative Study of Thermal Sensation in Man. PhD Thesis. Glasgow University: Scotland 1986. 